Egyptian

Orthodontic Journal

\title{
INFLUENCE OF FIRST PREMOLAR EXTRACTION ON MANDIBULAR THIRD MOLAR ANGULATION
}

\author{
Nagwa Enany ${ }^{1}$, Hassan Ismail ${ }^{2}$, Amira El Sammak ${ }^{3}$
}

ABSTRACT:

Objectives: To compare the changes in position of the developing mandibular third molars in both lower first premolar extraction and non extraction cases. Materials and Methods: Pretreatment and post treatment panoramic radiographs were taken of 15 subjects who had been treated by the extraction of the first mandibular premolars and 15 subjects who had been treated with nonextraction. The horizontal reference plane was used to measure and compare the changes in the inclination of the mandibular second molar and the developing third molars. The occlusal plane was used to measure the distance distal to the mandibular second molar. The distances from mesial cusp of mandibular third molar to occlusal plane and from distal cusp to occlusal plane were also measured. Results: The long axes of the mandibular third molar and second molars to horizontal reference plane pre treatment and post treatment had no statistically significant difference between both groups in the values of the angular changes pre and post treatment. The mean differences in the angle values between pre and post treatment for the right side and the left side showed no statistical significance difference between pre and post treatment in the two groups. A significant correlation was found between the two groups regarding the

1- Professor, Department of Orthodontics, Faculty of dentistry, Alexandria University.

2- Professor, Department of Orthodontics, Faculty of dentistry, Alexandria University.

3- Postgraduate student, Department of Orthodontics, Faculty of dentistry, Alexandria University. 
Egyptian

Orthodontic Journal

distance distal to the mandibular second molar to the ramus which increased more in the extraction group than in the non extraction group. Conclusion: premolar extractions will not ensure that the third molars will erupt normally or have sufficient space to achieve good alignment.

\section{INTRODUCTION}

The development of third molars and their influence on the dental arches has long been of concern to the dental profession ${ }^{(1)}$. Mandibular third molar impaction is a major problem in modern dentistry ${ }^{(2)}$.The developmental path of third molars in human beings is very irregular.

The effect of mandibular third molars on the relapse of mandibular incisor crowding following the cessation of retention in orthodontically treated patients has been a subject of much speculation.

Most mandibular third molar studies have concentrated on the influence that the third molars have on the rest of the dentition, rather than on the control that the rest of the dentition has on the third molars ${ }^{(4)}$. The causes for third molar impaction and prediction of third molar eruption have also been studied extensively. In contrast, the effect of orthodontic treatment on the developing third molars has not been subjected to many investigations.

The aim of this study was to compare the changes in position of the developing mandibular third molars in both lower first premolar extraction and non extraction cases.

\section{MATERIALS AND METHODS}

Panoramic radiographs of thirty orthodontic patients who had been treated by fixed orthodontic appliance at the Department of Orthodontics, Alexandria University were selected for the study. They were divided into two groups; group I: consisted of 15 panoramic radiographs of subjects whom their treatment plan included the extraction of the two mandibular first premolars. Group II: consisted of 15 panoramic radiographs of subjects who had been treated non-extraction. 
Egyptian

Orthodontic Journal

Inclusion criteria: Anchorage requirements for the cases collected were moderate. Age ranges between 12-20 years. Both groups have both mandibular $3^{\text {rd }}$ molars present before and after treatment showing mesioangular position. Not more than two thirds of the root development of the third molars has taken place before the orthodontic treatment. Full closure of the extraction space should be done by the end of treatment in extraction cases.

\section{Method:}

Panoramic radiographs pre-treatment and post-treatment of the 30 orthodontic patients fulfilling the selection criteria were selected. The thirty pre-treatment panoramic radiographs and the thirty post-treatment panoramic radiographs were traced manually and measured. The nasal septum and ANS were traced and bisected; a perpendicular line was drawn to this midline bisector that extended through the palatal shadow bilaterally. This constructed plane was termed the horizontal reference plane ${ }^{(3)}$. This plane was used to measure and compare the changes in the angles of the developing mandibular third molars and also the mandibular second molars for both the right and left sides. The occlusal plane was drawn on both sides.

The outlines of the mandibular second and third molars and their long axes were drawn on the tracing sheet.

The long axis of the second molar was traced from the mid-occlusal point through the midpoint of the root bifurcation whereas the long axes of the third molar buds were drawn by a perpendicular line bisecting a line connecting the mesial and distal outlines of the cervical areas

\section{The angles measured}

1) The outer angles formed by the third molar axes on both the right and left sides to the horizontal reference plane.

2) The outer angles formed by the second molars long axes on both right and left sides to the horizontal reference plane.

\section{Distances measured}

1) The distance distal to mandibular second molar to the ramus in line with the occlusal plane was measured to evaluate the space available for the developing mandibular third molar. 
2) The distance from mesial cusp of mandibular third molar to the occlusal plane and the distance from distal cusp of mandibular third molar to the occlusal plane for the evaluation of the change in position of the developing third molar.

The tracings were repeated after one week by the same investigator for more reliability.(fig 1)

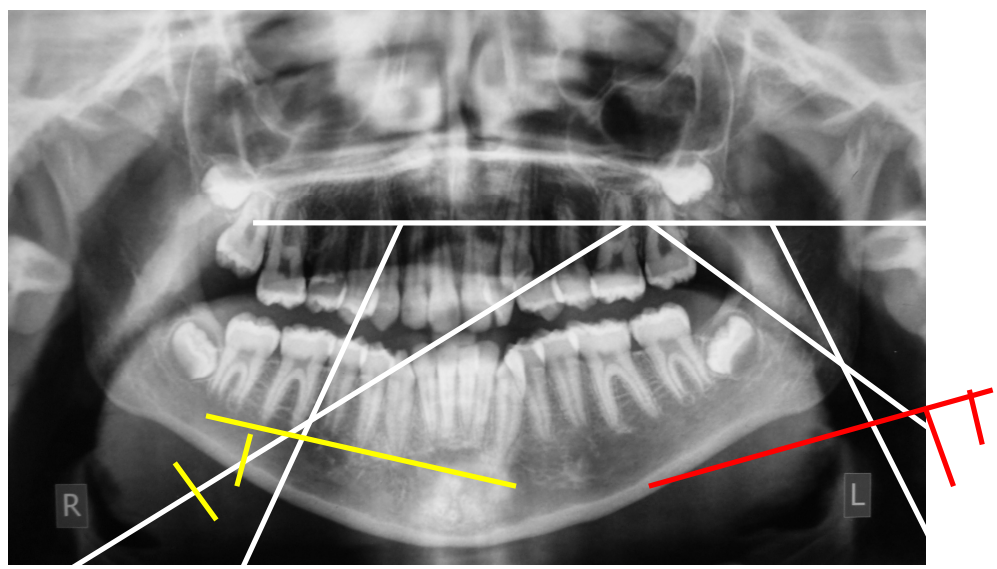

Fig.(1): Different planes, lines and measurements used to determine molars position.

\section{RESULTS}

Descriptive statistics were displayed as means and standard deviations of different measurements. Comparison between the two studied groups as regards to different measurements as well as difference in values between pre and post measurements was done using t test. Comparison between pre and post measurements in the same group was done using paired t test. Significance level of confidence was set at 5\%.

The Comparison of changes in the long axis of the right and left mandibular second and third molars relative to the HRP pre and post treatment between the two study groups is illustrated in table I. The influence of first premolar extraction on mandibular third molar angulation or mandibular second molar angulation relative to the mandibular plane or the horizontal reference plane was not significantly different between the two groups. 
Egyptian

Orthodontic Journal

Table I: Comparison of the angular changes in the long axis of the right and left mandibular third and second molars relative to the HRP pre and post treatment between the two study groups.

\begin{tabular}{|c|c|c|c|c|}
\hline & $\begin{array}{c}\text { Group I } \\
\text { Extraction cases } \\
\text { Mean } \pm \text { SD } \\
\mathbf{N}=\mathbf{1 5}\end{array}$ & $\begin{array}{c}\text { Group II } \\
\text { Non extraction cases } \\
\text { Mean } \pm \text { SD } \\
\mathbf{N}=\mathbf{1 5}\end{array}$ & T- test & P-value \\
\hline Rt $3^{\text {rd }} \mathrm{m}$. to HRP pre-T & $36.73 \pm 12.97$ & $40.73 \pm 13.44$ & 0.83 & 0.41 \\
\hline Rt $3^{\text {rd }}$ m. to HRP post-T & $39.07 \pm 18.93$ & $45.80 \pm 14.56$ & 1.09 & 0.28 \\
\hline $\begin{array}{l}\text { Paired t test } \\
\text { P value }\end{array}$ & $\begin{array}{l}0.55 \\
0.59\end{array}$ & $\begin{array}{l}1.49 \\
0.16\end{array}$ & & \\
\hline Difference & $2.33 \pm 16.38$ & $5.07 \pm 13.19$ & 0.50 & 0.62 \\
\hline $\mathrm{Lt} 3^{\text {rd }} \mathrm{m}$. to HRP pre-T & $42.00 \pm 17.74$ & $39.47 \pm 13.75$ & 0.44 & 0.67 \\
\hline $\mathrm{Lt} 3^{\text {rd }} \mathrm{m}$. to HRP post-T & $42.47 \pm 11.46$ & $42.87 \pm 10.76$ & 0.10 & 0.92 \\
\hline $\begin{array}{l}\text { Paired t test } \\
\text { P value }\end{array}$ & $\begin{array}{l}0.11 \\
0.92\end{array}$ & $\begin{array}{l}0.96 \\
0.35\end{array}$ & & \\
\hline Difference & $0.47 \pm 16.63$ & $3.40 \pm 13.66$ & 0.53 & 0.60 \\
\hline Rt $2^{\text {nd }} m$. to HRP pre-T & $61.93 \pm 8.39$ & $63.33 \pm 8.67$ & 0.45 & 0.66 \\
\hline Rt $2^{\text {nd }} \mathrm{m}$. to HRP post-T & $65.33 \pm 8.89$ & $65.93 \pm 10.21$ & 0.17 & 0.87 \\
\hline $\begin{array}{l}\text { Paired t test } \\
\text { P value }\end{array}$ & $\begin{array}{l}1.25 \\
0.23\end{array}$ & $\begin{array}{l}0.94 \\
0.36\end{array}$ & & \\
\hline Difference & $3.40 \pm 10.51$ & $2.60 \pm 10.73$ & 0.21 & 0.84 \\
\hline $\mathrm{Lt} 2^{\text {nd }} \mathrm{m}$. to HRP pre-T & $63.33 \pm 11.70$ & $62.07 \pm 9.20$ & 0.33 & 0.74 \\
\hline $\mathrm{Lt} 2^{\text {nd }} \mathrm{m}$. to HRP post-T & $63.53 \pm 8.05$ & $65.53 \pm 10.67$ & 0.58 & 0.57 \\
\hline $\begin{array}{l}\text { Paired } t \text { test } \\
\text { P value }\end{array}$ & $\begin{array}{l}0.07 \\
0.95\end{array}$ & $\begin{array}{l}1.84 \\
0.09\end{array}$ & & \\
\hline Difference & $0.20 \pm 11.27$ & $3.47 \pm 7.29$ & 0.94 & 0.36 \\
\hline
\end{tabular}

The comparison between the two groups regarding the difference from pre to post treatment in the distance of the mandibular second molar to the ramus, the depth of the mesial and distal cusps of the mandibular third molar in relation to the occlusal plane is illustrated in table II; It shows a significant increase in the distance distal to mandibular second molar after treatment in extraction cases $(p=0.006)$ with a mean of $4.0 \pm 3.52 \mathrm{~mm}$ whereas in non extraction cases the mean difference was $1.57 \pm 3.06 \mathrm{~mm}$. 
The changes in the depth of the mesial cusp of the mandibular third molar pre and post treatment was not significantly different between the two groups ( $\mathrm{p}=0.965)$, also the changes in the depth of the distal cusp of the mandibular third molar pre and post treatment was not significantly different between the two groups $(\mathrm{p}=0.632)$.

Table II: comparison of changes in the distance between the mandibular second molar and the ramus also the depth of the mesial and distal cusps of the mandibular third molar in relation to the occlusal plane pre and post treatment between the two study groups in $\mathrm{mm}$.

\begin{tabular}{|l|l|l|l|l|}
\hline & \multicolumn{1}{|c|}{$\begin{array}{c}\text { Group I } \\
\text { Extraction cases } \\
\text { Mean } \pm \text { SD }\end{array}$} & $\begin{array}{c}\text { Group II } \\
\text { Non extraction cases } \\
\text { Mean } \pm \text { SD }\end{array}$ & t & P \\
\hline $2^{\text {nd }} \mathrm{M}$ to Ramus & $4.0 \pm 3.52$ & $1.57 \pm 3.06$ & $2.856^{*}$ & 0.006 \\
\hline Mesial of $3^{\text {rd }} \mathrm{M}$ & $-0.33 \pm 3.48$ & $-0.30 \pm 2.20$ & 0.044 & 0.965 \\
\hline Distal of $3^{\text {rd }} \mathrm{M}$ & $-0.23 \pm 3.30$ & $0.13 \pm 2.56$ & 0.481 & 0.632 \\
\hline
\end{tabular}

$\mathrm{t}$ : Student t-test

*: Statistically significant at $\mathrm{p} \leq 0.05$

The percentile distribution of the studied mandibular right and left third molars for each case from both groups is illustrated in table III. There was no significance difference between the two groups $(\mathrm{p}=0.091)$.

Table III: The percentile distribution of the studied mandibular right and left third molars for each case from both groups.

\begin{tabular}{|l|c|c|c|c|}
\hline & $\begin{array}{c}\text { Increased } \\
\text { angulation }\end{array}$ & $\begin{array}{c}\text { Same } \\
\text { angulation }\end{array}$ & $\begin{array}{c}\text { Decreased } \\
\text { angulation }\end{array}$ & $\begin{array}{c}\text { Total } \\
\text { number }\end{array}$ \\
\hline Group I & 12 & 2 & 16 & 30 \\
extraction cases & $40 \%$ & $6.6 \%$ & $53.3 \%$ & 9 \\
\hline Group II & 20 & 1 & $30 \%$ & 30 \\
non extraction cases & $66.6 \%$ & $3.3 \%$ & & \\
\hline MCp & \multicolumn{4}{|c|}{0.091} \\
\hline
\end{tabular}

The percentile distribution of the studied mandibular right and left second molars for each case from both groups is illustrated in table IV. There was no significant difference between the two groups. $(p=0.918)$. 
Egyptian

Orthodontic Journal

Table IV: The percentile distribution of the studied mandibular right and left second molars for each case from both groups.

\begin{tabular}{|l|c|c|c|c|}
\hline & $\begin{array}{c}\text { improved } \\
\text { angulation }\end{array}$ & $\begin{array}{c}\text { Same } \\
\text { angulation }\end{array}$ & $\begin{array}{c}\text { Decreased } \\
\text { angulation }\end{array}$ & $\begin{array}{c}\text { Total } \\
\text { number }\end{array}$ \\
\hline Group I & 18 & 2 & 10 & 30 \\
\hline Extraction cases & $60 \%$ & $6.6 \%$ & $33.3 \%$ & \\
\hline Non extraction cases & 16 & 2 & 12 & 30 \\
\hline MCp & $53.3 \%$ & $6.6 \%$ & $40 \%$ & \\
\hline
\end{tabular}

MCp: $p$ value for Monte Carlo test

\section{DISCUSSION}

The results of this study had shown that the improvement in the angulation of mesioangular inclination of unerupted mandibular third molars is unpredictable; some showed improvement, others showed no change and some showed worse angulation.

Some studies ${ }^{(4,5)}$ have shown that panoramic radiographs are a reliable indicator in evaluating third molar positions, and so they were used in the present study. Some of the previous studies have used the occlusal plane ${ }^{(6-9)}$ as the horizontal plane of reference to measure treatment changes. However, Nanda ${ }^{(9)}$ and Broadbent ${ }^{(11)}$ showed that the palatal plane is more stable during growth and is not usually affected by orthodontic treatment. Even if such changes had taken place, they were likely to be small during the relatively short treatment period of the subjects in this study.

The horizontal reference plane was used in this study to measure the changes in the long axis of the mandibular third molars.

The linear measurements in this study showed that the distance distal to the mandibular second molar increased in extraction cases after treatment allowing more space for the third molar to.

This result is in agreement with $\mathrm{Kim}^{(12)}$ and Bayram, Ozer and Arici $^{(13)}$ who also found that the eruption space of the mandibular third molar increases with extraction 
The changes seen in the present study may be attributed to the mesial movement of the buccal segment following space closure.

Tarazona et $\mathrm{al}^{(14)}$ found that the angulations of mandibular third molar improves over time, regardless of whether the orthodontic treatment is undertaken with extractions or not. Haavikko et al ${ }^{(15)}$ claimed that extractions of mandibular premolars accelerated, but did not favor the eruption of the mandibular third molar.

However ,other authors such as Richardson et $\mathrm{al}^{(2)}$, Kim et $\mathrm{al}^{(12)}$, Jain and Valiathan ${ }^{(3)}$, observed that the extraction of premolars made more space in the molar area and, therefore, improved the angulations of the mandibular third molar compared to patients treated without extractions.

Authors such as Ricketts ${ }^{(17)}$ suggested that the probability of mandibular third molar eruption is directly related to the percentage of that molar found in front of the anterior border of the mandibular ramus, in such a way that, for a favorable eruption prognosis, half of the crown should be in front of the anterior border of the ramus.

In contrast, other authors such as Kim et al ${ }^{(12)}$ suggested that the space of the correct eruption of the mandibular third molar could be less than that previously observed by Ricketts ${ }^{(17)}$

A study by Elsey and Rock ${ }^{(6)}$ showed an improvement of third molar angulations by a mean of 7 degrees. However, these authors did not compare the changes on the right and left sides, and no comparisons were made with a representative group of non-extraction patients.

Richardson $^{(2)}$ stated that the original space conditions in extraction cases may have more influence on the eruption of third molars than do the premolars extractions.

Results were also coinciding with $\operatorname{Artun}^{(18)}$ et al findings who suggested that premolar extraction therapy has a favorable effect on maxillary third molar angulations, while changes in mandibular third molar angulations during treatment may be similar in patients treated with and without premolar extractions . 
Egyptian

Orthodontic Journal

Although it is not possible to predict from the results how many third molars would erupt fully later on, it is clear that the improved positions would facilitate surgery for many of these teeth that did ultimately require removal. It is recommended that third molar angulations be included in the treatment planning of borderline extraction cases.

Orthodontists should advise patients that premolar extractions will not ensure that the third molars will erupt and have sufficient space to achieve good alignment but if they do not erupt they may need less surgical procedures for removal.

\section{REFERENCES}

1. Staggers JA, Germane N, Fortson WM. A comparison of the effects of first premolar extractions on third molar angulation. Angle Orthod. 1992 Summer;62(2):135-8.

2. Richardson ME. The etiology and prediction of mandibular third molar impaction. Angle Orthod. 1977;47(3):165-72.

3. Jain S, Valiathan A. Influence of first premolar extraction on mandibular third molar angulation. Angle Orthod. 2009 Nov;79(6):1143-8.

4. Olive RJ, Basford KE. Transverse dentoskeletal relationships and third molar impaction. Angle Orthod. 1981; 51:41- 47.

5. Larheim TA, Svanaes DB. Reproducibility of rotational panoramic radiography: mandibular linear dimensions and angles. Am J Orthod Dentofacial Orthop. 1986; 90:45-51.

6. Elsey MJ, Rock WP. the influence of orthodontic treatment on development of third molars.Br J Oral Maxillofac Surg. 2000;38 (4):350-3

7. Larheim TA, Svanaes DB. Reproducibility of rotational panoramic radiography: mandibular linear dimensions and angles. Am J Orthod Dentofacial Orthop. 1986; 90:45-51.

8. Yigit M, Gokce D, Kocadereli I, Tasar F. The effects of first premolar extractions on third molar angulations. Angle Orthod. 2005; 75:719-722. 
9. Nanda RS. Reappraising “Wits." Readers' forum. Am J Orthod Dentofacial Orthop. 2004; 125:18

10. Badawi F J, Levy JC, Yazbeck C, Cavezian R, Cabanis EA. Eruption of third molars: relationship to inclination of adjacent molars. Am J Orthod Dentofacial Orthop. 2004 Feb; 125(2):200-2.

11. Broadbent, B.H. The face of the normal child. Angle Orthod. 1937;7:4:183-208.

12. Kim TW, Artun J, Behbehani F, Artese F. The prevalence of third molar impaction in patients treated with nonextraction and with extraction of 4 premolars. Am J Orthod Dentofacial Orthop. 2003; 123(2):138-45.

13. Bayram M, Ozer M, Arici S. The effects of first molar extraction on third molar angulation and eruption space. Oral Surg Oral Med Oral Pathol Oral Radiol Endod. 2009 Feb;107(2):e14-20.

14. Tarazona BA, Paredes VB, Llamas JM, Cibrian RE, Gandía JL. Influence of first and second premolar extraction or non-extraction treatments on mandibular third molar angulation and position. A comparative study. Med Oral Patol Oral Cir Bucal. 2010 Sep 1; 15(5):e760-6.

15. Haavikko K, Altonen M, Mattila K. Predicting angulational development and eruption of the lower third molar. Angle Orthod. 1978; 48(1):39-48

16. Ricketts RM. The principle of racial growth of the mandible. Angle Orthod.1972; 42:368.

17. Artun J, Thalib L, Little RM. Third molar angulation during and after treatment of adolescent orthodontic patients. Eur J Orthod. 2005 Dec;27(6):590-6. 